\title{
Performance and Emission Characteristics of Biodiesel-Butanol Blended Fuel in LHR Engine
}

\author{
S. Muthukumarasamy ${ }^{\dagger}$, S. Arun, P. Amirthalingam, P. Yogesh and P. Baradhan \\ Department of Mechanical Engineering, Vel Tech, Avadi, Chennai- 600062, India \\ †Corresponding Author Email: muthukumarasamy@veltechengg.com
}

(Received May 15, 2018; accepted July 18, 2018)

\begin{abstract}
The use of biodiesel as an alternative diesel engine fuel is increasing rapidly. However, due to technical deficiencies, they are rarely used purely or with high percentages in diesel engines. Therefore, in this study, we used butanol as an additive to research the possible use of higher percentages of biodiesel in a diesel engine. B100 (100\% biodiesel) was prepared as the baseline fuel. Butanol was added to biodiesel as an additive by volume percent of $5 \%, 10 \%, 15 \%$ 20\%(denoted as B95 but5, B90 but10, B85 but15 and B80 but20), were used in a single cylinder, four strokes direct injection LHR engine. The effect of test fuels on brake specific fuel consumption, brake thermal efficiency, exhaust gas temperature, and NOX, smoke opacity emission was investigated. The experimental results showed that the performance and emission of LHR engine we can use of the $100 \%$ biodiesel. Besides, the exhaust emissions for B80 but 20 were fairly reduced.
\end{abstract}

Keywords: Biodiesel; LHR engine; Performance characters; Emission characters.

\section{INTRODUCTION}

Diesel engines are widely used as power sources in medium and heavy-duty applications because of their lower fuel consumption and lower emissions of NOX compared with gasoline engines. Rudolf Diesel, the inventor of the diesel engine, ran an engine on groundnut oil at the Paris Exposition of 1900. Since then, palm oils have been used as fuels when petroleum supplies were expensive or difficult to obtain. Since the oil crisis of the 1970s research interest has expanded in the area of alternative fuels by Monyen (1998) and McDonnell (1995). The high viscosity and low volatility of raw vegetable oils are generally considered to be the major drawbacks for their utilization as fuels in diesel engines. The low volatility leads to oil sticking to the injector or cylinder walls, resulting in deposit formation. However, these effects can be eliminated or reduced through esterification of the oil to form monoesters. The process of transesterification removes glycerol from the triglycerides and replaces it with radicals from the alcohol used for the conversion process. This process decreases viscosity and improves the cetane number and heating value. These monoesters are known as biodiesel Monyen et al. (2001), Perkins (1991) and Zhang (1988). Thermal barrier coatings are used to improve reliability and durability of hot section metal components and enhance engine performance and efficiency in internal combustion engines Vijayakumar (2017). Thermal barrier coatings are stabilized zirconia as a top coat that provides thermal insulation toward metallic substrate. The thermal barrier coated engine parts are piston, cylinder head, cylinder liners and exhaust valves. The engine that thermal barrier coating is applied is called low heat rejection (LHR) engine. Insulating the combustion chamber components of LHR engine can reduce heat transfer between in-cylinder gas and cylinder liner. The LHR concept is based on suppressing heat rejection to the coolant and recovering the energy in form of useful work.

Some important advantages of LHR engines are improved fuel economy, reduced engine noise, higher energy in exhaust gases and multi-fuel capability of operating low cetane fuels by Zhou (2007), Uzun (1999) and Parlak (2005). Average incylinder gas temperatures increase due to insulation in LHR engines. In compression stroke around TDC in-cylinder gas temperature increases by $250 \mathrm{~K}$ in LHR engine in comparison to standard engine. This reduce ignition delay period of fuel injected to cylinders. Godwin (2017) investigated and found out the optimum parameters for obtaining the best performance using alternate fuels of linseed oil. Lakshmanan (2017) analysed about the usage of chicken fat oil blended with diesel fuel in a compression ignition engine.

The concept of a LHR engine is believed to be 
useful in this regard. The increased in-cylinder gas and cylinder liner temperatures of the LHR engine make possible the usage of biodiesel without preheating. So the energy of biodiesel can be released more efficiently. There have been many studies about LHR engines and biodiesel usage in standard diesel engines in the literature by $\mathrm{Ma}$ (1999). However, there have not been many studies about biodiesel usage in LHR engines. So, this area has not been well understood. Prasad (2000) tested a single-cylinder diesel engine with Superni-90 coated piston top and cylinder liner of which had a maximum engine power of $3.68 \mathrm{~kW}$ and a compression ratio of 16:1. They used raw jatropha and pongamia oils and esterified jatropha oil as fuels. They found that the performance of the LHR engine improved, nitrogen oxide (NOx) levels decreased and exhaust gas temperatures were increased. The objective of this study is to apply LHR engine for improving engine performance when biodiesel is used as an alternative fuel and to control emission properties by Lakshmanan (2017). Venkatesh et al. (2016) studied the flow of heat and fluid in solar air heater using Computational Fluid Dynamics (CFD). The predicted temperature results were observed within a deviation of $\pm 10.64 \%$.

\section{MATERIAL AND METHOD}

\subsection{Catalyst Preparation}

Potassium hydroxide $(\mathrm{KOH})$ catalyst amount was weighed using an electronic weighting machine. Methanol measured using the measuring jar according to the molar ratio was taken in a conical flask. The weighted catalyst was put in the conical flask containing methanol and was mixed well using, the magnetic stirrer for 5 minutes for complete dissolution of $\mathrm{KOH}$ in the methonal.

\subsection{Transesterification Process}

The palm oil is taken in conical flask kept in the heater to heat the oil. Then oil heat is heated to $70^{\circ} \mathrm{c}$.The methanol and catalyst (potassium hydroxide) mixed is pour into the preheat palm oil. The reaction flask is then placed in the magnetic stirrer with hot plate and the measurement of time is started at this point. The reaction mixture remained for $1 \frac{1 / 2}{2}$ hours at a temperature of $65^{\circ} \mathrm{C}$ and with a constant stirring. Heating and stirring are continued for reaction time at atmospheric pressure. It is then stirred well for $1 \frac{1 / 2}{2}$ hours using magnetic stirrer. Molar ratio of methanol to palm oil used was 15:1.

\subsection{Separation Process}

After the completion of the transesterification process. The methyl ester mixture pour in to the separating flask. Then ester mixture formed at the upper layer and the glycerol form in the lower layer. Then separated the ester and glycerol form the separating flask.

\section{LHR ENGINE DEVELOPMENT}

The piston, cylinder head and Value coating thickness is about $120-150$ microns. The coating method plasma spray coating. The engine combustion chamber is coated with partially stabilized Zirconia. After completion of the coating process, the engine was allowed to run an hour and the experiment was conducted on it.

Table 1 Fuel properties

\begin{tabular}{|c|c|c|}
\hline Properties & Biodiesel & Butanol \\
\hline $\begin{array}{c}\text { Density } \\
\text { (kg/m3) }\end{array}$ & 882 & 810 \\
\hline $\begin{array}{c}\text { Kinematic viscosity } \\
\text { @40 C } \\
(10-6 \text { m2/sec })\end{array}$ & 4.63 & 3.64 \\
\hline Flash point & 128 & 35 \\
\hline
\end{tabular}

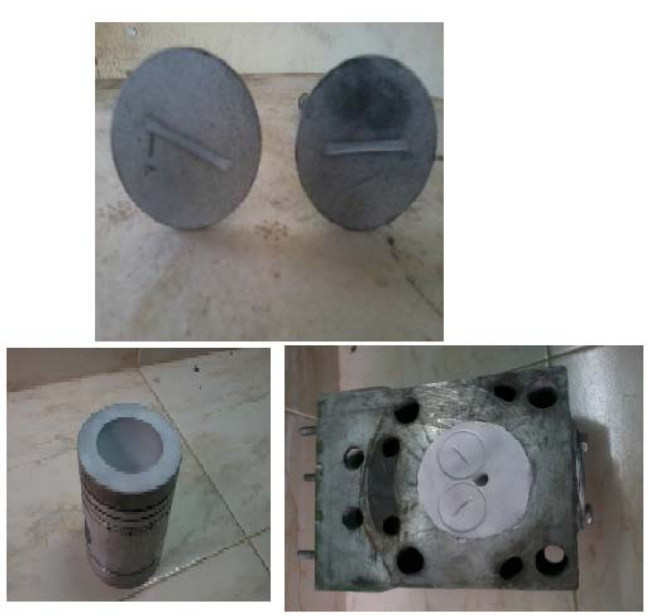

Fig. 1. Photographic view of piston, cylinder head and value after coating.

\section{EXPERIMENTAL PROCEDURE}

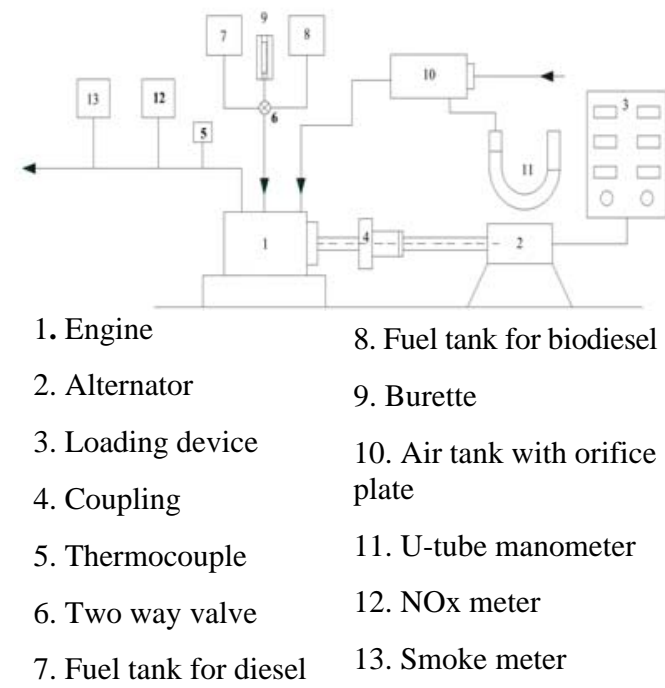

The experiments were carried out on a naturally aspirated, water-cooled, single cylinder, diesel engine. The specifications of the engine are shown in Table 2. The engine was connected to an eddy current dynamometer, and running at constant speed of $1500 \mathrm{rpm}$. A schematic diagram of the engine 
setup is shown in Fig. 2. The test was started firstly with diesel fuel and when the engine reached the operating temperature, it was loaded with a eddy current dynamometer. The load is varied from 0 to $3 \mathrm{kw}$. The number of cylinder used is one. The property value of biodiesel and butanol is shown in table 1 . The performance tests were carried on a single cylinder, four strokes and water cooled, KIRLOSKAR diesel engine. The engine was directly coupled to an eddy current dynamometer.

Table 2 Engine specifications

\begin{tabular}{|c|c|}
\hline Make & kirloskar \\
\hline Speed & $1500 \mathrm{RPM}$ \\
\hline No. of cylinder & One \\
\hline Bore & $80 \mathrm{~mm}$ \\
\hline Stroke & $110 \mathrm{~mm}$ \\
\hline Rated output & $3 \mathrm{~kW}$ \\
\hline Compression ratio & $16.5: 1$ \\
\hline Orifice diameter & $20 \mathrm{~mm}$ \\
\hline Type of ignition & Compression ignition \\
\hline Method of loading & Resistance loading \\
\hline Method of starting & crank start \\
\hline
\end{tabular}

The engine was run at a constant speed of 1500 rpm, Continuous water supply is given to the engine for the cooling. The air box with an orifice meter and water manometer is used to measure the flow rate of air supplied to the engine .Two separate fuel tanks were used; one for diesel and the other for biodiesel. The volumetric flow of fuel is measured using burette and a stop watch Smoke is measured by AVL make Hatridge type smoke meter. The NOX emission is measured by Technovation make NOX meter which uses chemical sensor. Experiment were conducted at five engine loads .The emission parameter measured are NOX and smoke opacity. The Compression ratio is $16.5: 1$.The exhaust gas temperature was measured using digital temperature indicator. we used butanol as an additive to research the possible use of higher percentages of biodiesel in a diesel engine. B100 (100\% biodiesel) was prepared as the baseline fuel. Butanol was added to biodiesel as an additive by volume percent of $5 \%, 10 \%, 15 \% 20 \%$ (denoted as B95 but5, B90 but10, B85 but15 and B80 but20), were used in a single cylinder, four strokes direct injection diesel engine.

The performance and emission characteristic of a constant speed, single cylinder 5 hp LHR engine was determined using various fuel blends. The engine performance such as Brake specific fuel consumption, total fuel consumption, brake thermal efficiency and exhaust gas temperature, smoke opacity and NOx emission were determined. The fuel consumption was determined by measuring the time taken for a fixed volume of fuel to flow into the engine. The air was supplied to the engine through an air box with an orifice plate placed on one of its sides. The air flow rate to the engine was determined by measuring the pressure across the orifice plate with the aid of a U-tube manometer.

The exhaust gas temperature was measured using copper-constantan thermocouples connected to a temperature indicator. Smoke opacity is analyzed using the smoke meter. The exhaust gas was analyzed to find out the NOx emission. The content of NOx in parts per million (ppm) was measured using a NOx analyzer consisting of an electrochemical sensor. The observations made during the test included the brake load, engine speed, and time taken for consumption of fuel, drop in air pressure across the orifice meter, exhaust gas temperature, smoke opacity and exhaust gas emissions of NOx. The performance parameters such as brake specific fuel consumption and brake thermal efficiency were calculated.

\section{RESULTS AND DISCUSSION}

\subsection{Brake Specific Fuel Consumption}

Fig 3 shows the variation of specific fuel consumption (BSFC) for the engine using diesel, biodiesel, biodiesel-butanol blend with different volume basics as $(95+5),(90+10),(85+15),(80$ +20 ) with respect to BMEP. The BSFC is defined as the ratio of mass fuel consumption to the brake power. Due to the reduction effect of butanol on the energy content of the blends, there is usually increase in BSFC. Among the fuels tested the lowest BSFC values are obtained with diesel fuel due to low fuel consumption rate and high brake power. There are significant increases in BSFC especially when the engine is fuelled with blends having high butanol content.

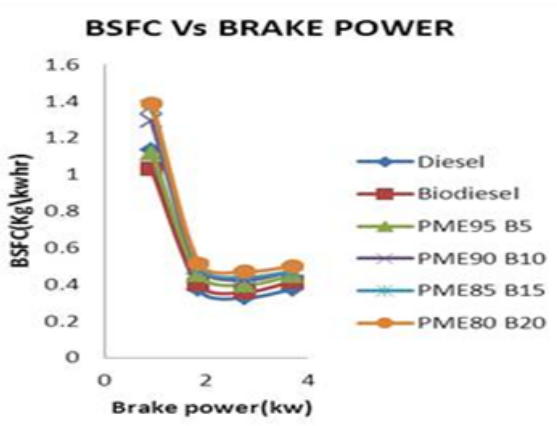

Fig. 3. BSFC vs BP

\subsection{Brake Thermal Efficiency}

Fig 4 shows compares the brake thermal efficiency using biodiesel and butanol to that of blends $(5,10$, 15 \& 20) butanol respectively. It is evident that thermal efficiency with butanol was lower than diesel at all brake mean effective pressure. The possible reasons for the reduction in thermal efficiency may be the lower heat content, higher viscosity and poor volatility of butanol compared to diesel. The graph shows brake thermal efficiency is more are less equal for diesel and 100\% biodiesel.

\subsection{Exhaust Gas Temperature}

Fig 5 shows the variation of exhaust gas temperature 
with respect to brake mean effective pressure for the engine using biodiesel-butanol blends (5, 10, 15 \& 20) of butanol. The exhaust gas temperatures with the blends are lowered than that with diesel. This may attributed to the lower energy content of the blend as a result of the oxygen content and their lower cetane number. The highest decrease in the exhaust temperature was observed in the $100 \%$ biodiesel and in the blend of but 15 , but 20 which has lowest energy content among the fuels tested.

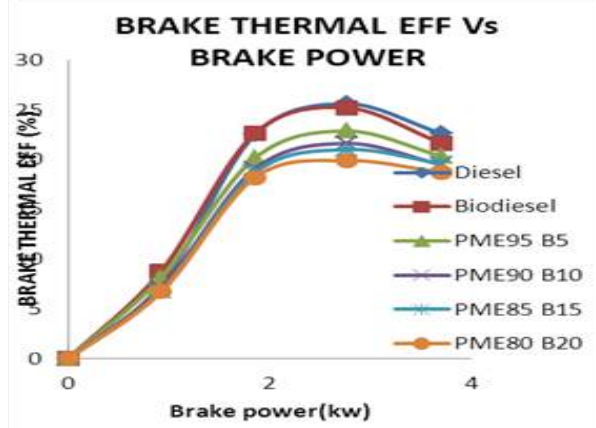

Fig. 4 BTE vs BP

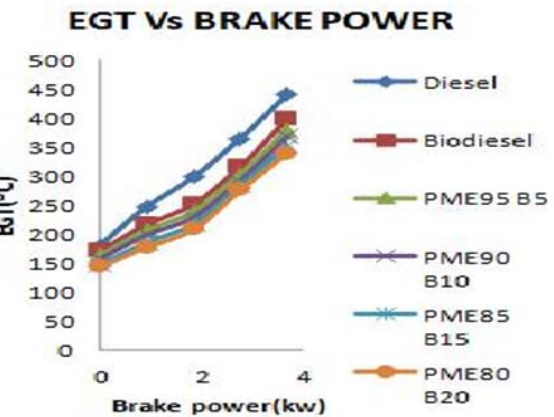

Fig. 5. Brake power Vs Exhaust gas temperature

\subsection{NOX Emission:}

Fig 6 shows that there is a decreasing tendency in $\mathrm{NO}_{\mathrm{x}}$ emissions with the use of the blends as compared to diesel fuel, the decrease in $\mathrm{NO}_{\mathrm{x}}$ emissions is usually proportional to the butanol content in the blends. $\mathrm{NO}_{\mathrm{x}}$ emissions from the diesel engine depend on various reasons such as fuel properties and engine operating conditions It is known that $\mathrm{NO}_{\mathrm{x}}$ emissions are caused by higher combustion temperature and higher oxygen concentration in the cylinder. Alcohols usually produce lower combustion temperature due to their lower heating value and oxygen content. Above graph also indicates that the $\mathrm{NO}_{\mathrm{x}}$ emission was lowered with the substitution of butanol as fuel.

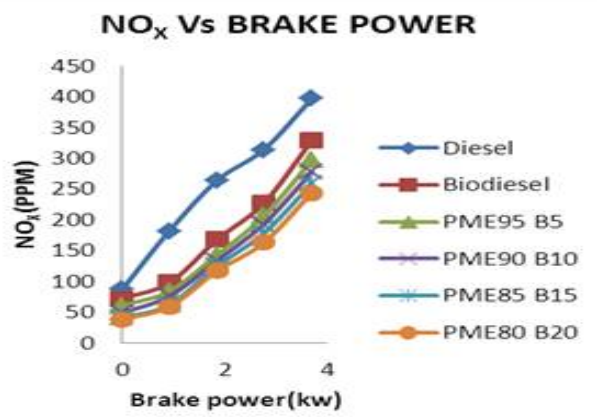

Fig. 6. Brake Power vs NOx

\subsection{Smoke Opacity:}

Smoke opacity defines as darkness of smoke due to carbon content. Above graph shows the comparison of smoke opacity for different percentage of butanol in biodiesel. For all BMEP it is found that smoke opacity gradually decreases as percentage of butanol in biodiesel increases. The maximum decreases in the smoke opacity are seen at the blends of but $15 \%$ and but $20 \%$.

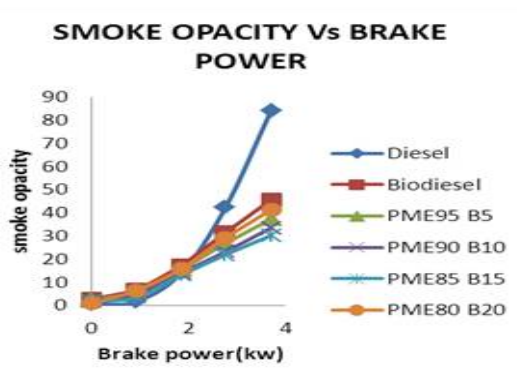

Fig. 7. Smoke opacity vs BP

\section{CONCLUSION}

The engine performance and exhaust emissions of a LHR engine using biodiesel- butanol blends were investigated and compared to those with baseline fuel. The blends containing (B95 + but5), (B95 + but10), (B85 + but15), (B80 + but20) were prepared and tested in a LHR engine. There are significant increases in BSFC especially when the engine is fuelled with blends having high butanol content because of higher fuel consumption rates and reduction in brake power. The brake thermal efficiency of the fuel blends is very close to the biodiesel. The use of biodiesel - butanol fuel blends caused a decrease in NOX emissions. The formation of exhaust emissions was heavily affected by the butanol content of the blend. The exhaust gas temperatures with the blends are lowered than that with diesel. For all BMEP it is found that smoke opacity gradually decreases as percentage of butanol in biodiesel increases. The maximum decreases in the smoke opacity are seen at the blends of but $15 \%$ and but $20 \%$.

\section{REFERENCES}

Godwin Antony. A., S. Dinesh, K. Rajaguru, V. Vijayan (2017). Analysis and Optimization of Performance Parameters in Computerized I.C. Engine Using Diesel Blended with Linseed Oil and Leishmaan's Solution, Mechanics and Mechanical Engineering 21(2) 193-205.

Lakshmanan, P., P. Kaliyappan, M. Ranjithkumar, K. Aravinth, D. Vakkachan, C. Moorthy and S. Kumar (2017). An Experimental Investigation to Study the Performance and Emission Characteristics of Chicken Fat Oil Fuelled DI Diesel Engine, Journal of Applied Fluid Mechanics 10, Special Issue 85-91.

Ma, F. and M. Hanna (1999). Biodiesel production: a review. Biosource Technol 70, 1-15. 
McDonnell, K., S. Ward D. and Timoney (1995). Hot water degummed rapeseed oil as a fuel for diesel engines. J Agric Eng Res 60, 7-14.

Monyem, A. (1998). The effect of biodiesel oxidation on engine performance and emissions, $\mathrm{PhD}$ thesis, Iowa State University.

Monyem, A. and J. H. Van Gerpen (2001). The effect of biodiesel oxidation on engine performance and emissions. Biomass Bioenergy 20, 317-25.

Parlak, A., Yasar H., Eldog an O. (2005). The effect of thermal barrier coating on a turbo-charged diesel engine performance and exergy potential of the exhaust gas. Energy Convers Manage 46, 489-99.

Perkins, L. A., C. L. Peterson, D. L. Auld (1991). Durability testing of transesterified winter rape oil as fuel in small bore, multi-cylinder, DI, CI engines. SAE paper no. 911764.

Prasad, C. M. V., M. V. S. M. Krishna Reddy, C. P., K. R. Mohan (2000). Performance evaluation of non-edible vegetable oils as substitute fuels in low heat rejection diesel engines. Proc Instrum Mech Eng 214 (D), 1817.

Uzun, A., C., I. Evik, M. Akcil (1999). Effects of thermal barrier coating on a turbocharged diesel engine performance. Surf Coat Technol, 116119, 505-7.

Venkatesh, R. and V. Vijayan (2016). Performance Evaluation of Multipurpose Solar Heating System, Mechanics and Mechanical Engineering 20(4), 359-370.

Vijayakumar, M. and P. C. Mukesh kumar (2017). Performance Enhancement and Emissions Analysis of Diesel Engine with Biodiesel, NPropanol and 1-Butanol Blend. Journal of Applied Fluid Mechanics, 79-84.

Zhang, Q., M. Feldman, C. L. Peterson (1988). Diesel engine durability when fueled with methyl ester of winter rapeseed oil. ASAE paper no. 881562.

Zhou, H., D. Yi, Z. Yu, L. Xiao (2007). Preparation and thermophysical properties of $\mathrm{CeO} 2$ doped La2Zr2O7 ceramic for thermal barrier coatings. J Alloys Compds 438, 217-21. 